\title{
TRATAMENTO DE EFLUENTES DA INDÚSTRIA DE CONSERVAS DE PEIXE COM VISTA À SUA REUTILIZAÇÃO
}

\author{
R. O. CRISTÓVÃO ${ }^{1}$, C. M. BOTELHO ${ }^{1}$, R. J. E. MARTINS ${ }^{1,2}$, J. M. LOUREIRO ${ }^{1}$ e R. A. R. \\ BOAVENTURA $^{1}$
}

${ }^{1}$ Laboratory of Separation and Reaction Engineering (LSRE), Associate Laboratory LSRE/LCM, Departamento de Engenharia Química, Faculdade de Engenharia, Universidade do Porto, Rua do Dr. Roberto Frias, 4200-465 Porto, Portugal

${ }^{2}$ Departamento de Tecnologia Química e Biológica, Escola Superior de Tecnologia, Instituto Politécnico de Bragança, Campus de Santa Apolónia, 5301-857 Bragança, Portugal E-mail para contato: raquel.cristovao@fe.up.pt

RESUMO - É de grande interesse ambiental e económico estudar o tratamento de efluentes da indústria de conservas de peixe de forma a obter uma água com os requisitos de qualidade necessários para considerar a sua reutilização e/ou reciclagem para a unidade industrial. No entanto, o elevado conteúdo de sal tem sido um fator limitante, pois persiste mesmo após o tratamento convencional dos efluentes. Assim, foi estudado e otimizado um processo de clarificação por filtração rápida, osmose inversa e desinfeção UV, como tratamento de afinação do efluente previamente tratado, de modo a remover sólidos, sais e microrganismos remanescentes. Este tratamento de afinação permitiu alcançar eficiências de remoção de $78 \%$ de sólidos suspensos totais, 97,3\% de carbono orgânico dissolvido, 99,8\% de azoto total solúvel, 99,1\% de condutividade, acima de $96 \%$ de aniões e catiões e $100 \%$ de bactérias heterotróficas (UFC), atingindo-se, como pretendido, água com os requisitos de qualidade necessários para ser reutilizada ou reciclada para a unidade industrial. Consequentemente, é possível uma redução da descarga de efluentes, uma limitação do uso de água e uma redução dos custos associados.

\section{INTRODUÇÃO}

A indústria de conservas de peixe consome uma grande quantidade de água (tipicamente $15 \mathrm{~m}^{3} / \mathrm{t}$ peixe processado) em operações de limpeza, lavagem, arrefecimento, descongelação, etc. (AWARENET, 2005). Consequentemente, este setor gera também grandes quantidades de águas residuais cujo tratamento é particularmente difícil devido ao alto teor em matéria orgânica, sais e óleos e gorduras que apresentam (COWI, 2000). Adicionalmente, os seus efluentes também apresentam variações significativas dependendo da matéria-prima processada e da altura do dia em que são descarregados, pelo que se torna difícil o seu tratamento de forma a cumprir os valores limite de emissão (VLE) para a descarga de águas residuais industriais (Decreto-Lei $\mathrm{n}^{\circ}$ 236/98). Desta forma, é de extrema importância o estudo do tratamento deste tipo de efluentes de modo a cumprir os requisitos impostos pela legislação, assim como, tanto por razões de sustentabilidade ambiental como económicas, equacionar o seu tratamento de modo a obter uma água com requisitos de qualidade que 


\section{9 a 22 de outubro de 2014 \\ Florianópolis/SC}

permitam a sua reutilização ou reciclagem para o processo industrial (AWARENET, 2005).

O tratamento convencional de efluentes com características semelhantes aos das indústrias de conservas de peixe normalmente engloba um tratamento primário para remoção das partículas em suspensão no efluente (sólidos suspensos totais, óleos e gorduras, etc.) e um tratamento secundário para degradação da matéria orgânica presente no efluente. O tratamento primário pode incluir uma decantação, uma flutuação por ar dissolvido ou uma coagulação-floculação química (Ela e Nawar, 1980; Peleka e Matis, 2008). O tratamento secundário deste tipo de efluentes é efetuado essencialmente por métodos biológicos, quer aeróbios, quer anaeróbios (Chowdhury et al., 2010). No entanto, após estes tratamentos, os efluentes ainda apresentam uma elevada salinidade, pelo que, para a reutilização da água no processo industrial, é necessário equacionar um tratamento de clarificação final. Existe uma vasta gama de membranas desenvolvidas para o tratamento de água salgada e para a produção de água doce a partir de água com diferentes salinidades. Hoje em dia, os processos de membranas mais utilizados no tratamento de água salina são a osmose inversa (Misdan et al., 2012) e a nanofiltração (AlTaee e Sharif, 2011). No entanto, o processo de osmose inversa apresenta várias vantagens, mostrando ser uma tecnologia atrativa para a separação do conteúdo salino dos efluentes, devido à sua confiabilidade, à sua elevada taxa de recuperação de água e de rejeição de sal e à sua capacidade de tratar uma ampla gama de concentrações de água do mar (Al-Mutaz, 1996; Peñate e García-Rodriguez, 2012). Contudo, para a reutilização de um efluente numa indústria alimentar é também necessário considerar a sua qualidade bacteriológica, isto é, assegurar a sua desinfeção. Nos últimos anos, a desinfeção por radiação ultravioleta (UV) tem sido cada vez mais utilizada para a inativação de bactérias, sem a formação de subprodutos tóxicos (Hijnen et al., 2006).

Este trabalho tem como objetivo o estudo e a otimização do tratamento de clarificação de um efluente de uma indústria de conservas de peixe previamente tratado, para reutilização e/ou reciclagem no processo industrial. Este tratamento consiste numa filtração rápida, numa osmose inversa e numa desinfeção UV, de modo a remover sólidos, sais e microrganismos remanescentes.

\section{MATERIAIS E MÉTODOS}

\subsection{Caracterização do efluente}

O efluente utilizado neste trabalho, foi um efluente de uma indústria de conservas de peixe do norte de Portugal, já previamente sujeito a um tratamento convencional, composto por uma etapa de sedimentação, por um tratamento por coagulação-floculação química e por um tratamento biológico aeróbio por lamas ativadas.

A caracterização do efluente relativamente aos sólidos suspensos totais (SST), ao carbono orgânico dissolvido (COD), ao azoto total dissolvido $\left(\mathrm{N}_{\text {total dissolvido }}\right)$, aos aniões e aos catiões presentes no efluente, foi efetuada de acordo com o Standard Methods for the Examination of Water and Wastewater (APHA, 2005). Para a medição do COD foi utilizado um analisador Shimadzu 5000A Total Organic Carbon. Os valores obtidos representam a média de pelo menos duas medidas; na maioria dos casos a amostra é injetada três vezes e a validação é efetuada pelo equipamento apenas quando obtém um coeficiente de variação (CV) inferior a $2 \%$. A condutividade a $20{ }^{\circ} \mathrm{C}$ foi 


\section{9 a 22 de outubro de 2014 \\ Florianópolis/SC}

determinada com uma sonda de condutividade (WTW TetraCon 325) e um medidor de condutividade (WTW LF538). Os aniões foram medidos por cromatografia iónica (Dionex ICS-2100) utilizando um Dionex Ionpac composto por uma coluna AS 11-HC 4 x $250 \mathrm{~mm}$ e um supressor ASRS $3004 \mathrm{~mm}$. Os catiões foram analisados também por cromatografia iónica (Dionex DX-120), utilizando um Dionex Ionpac composto por uma coluna CS12A 4 x $250 \mathrm{~mm}$ e um supressor CSRS $3004 \mathrm{~mm}$. A eluição isocrática foi efetuada com $\mathrm{NaOH} 30 \mathrm{mM}$ e ácido metanossulfónico $20 \mathrm{mM}$ a um caudal de 1,5 e 1,0 mL/min para análise dos aniões e catiões, respetivamente.

\subsection{Filtração}

$\mathrm{Na}$ etapa de filtração utilizou-se um filtro rápido $(50 \mathrm{~cm}$ de altura e $11,3 \mathrm{~cm}$ de diâmetro interno) composto por uma camada de $40 \mathrm{~cm}$ de areia (densidade $2,6 \mathrm{~g} / \mathrm{cm}^{3}$ ) com diâmetro entre 0,5 e $1 \mathrm{~mm}$. Foram colocadas duas camadas de gravilha de $5 \mathrm{~cm}$, uma no topo e outra no fundo do filtro, de forma a distribuir melhor a água pela coluna de areia e a funcionar como meio de suporte, respetivamente. $\mathrm{O}$ filtro foi desenhado e operado de forma a proporcionar uma velocidade média de filtração de $2,4 \mathrm{~m}^{3} \cdot \mathrm{m}^{-2} \cdot \mathrm{d}^{-1}$. A eficiência do filtro de areia foi determinada através da redução de SST.

\subsection{Osmose inversa}

A instalação piloto utilizada no tratamento por osmose inversa foi o modelo RO 250 da AQUAQUÍMICA, Lda. (Figura 1) que permite um caudal máximo de $250 \mathrm{~L} / \mathrm{h}$ e uma pressão entre 7 e 15 bar. Os testes foram efetuados aos caudais de 192, 198 e $216 \mathrm{~L} / \mathrm{h}$. A pressão foi mantida entre 9,0 e 10,0 bar. O caudal de alimentação e a pressão de operação foram ajustados através das válvulas de controlo das correntes de recirculação e de concentrado e visualizados em medidores de pressão e de

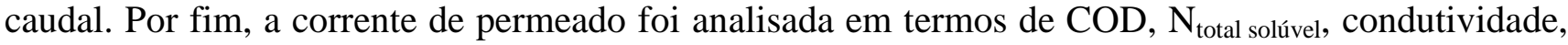
aniões e catiões.

\subsection{Desinfeção UV}

O equipamento de desinfeção UV é composto por uma lâmpada de descarga de $45 \mathrm{~W}$ de mercúrio de baixa pressão, filtros de 1 e $5 \mu \mathrm{m}$, uma câmara de aço inoxidável AISI 304, um medidor de tempo e bobinas eletrónicas, tudo dentro de um reator cilíndrico de aço AISI 316 L (Figura 2). O efluente clarificado proveniente do sistema de osmose inversa segue diretamente para o sistema de desinfeção por UV. São recolhidas amostras após a desinfeção e, de seguida, o efluente segue para o sistema de esgoto. As amostras antes e após a desinfeção são analisadas relativamente à presença de microrganismos, efetuando uma contagem das bactérias heterotróficas pelo método do espalhamento em placas de meio AGAR. Por fim, as placas são incubadas a 22 e a $37^{\circ} \mathrm{C}$, durante 24 e $48 \mathrm{~h}$. 


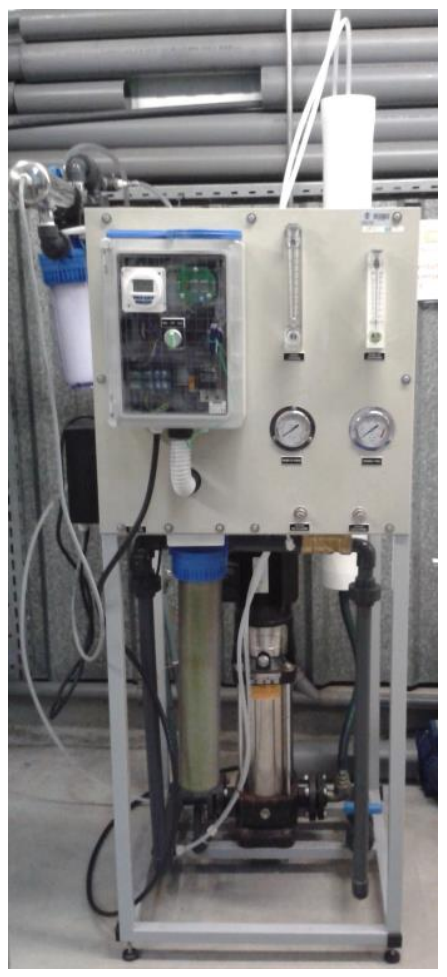

Figura 1 - Instalação piloto para estudos de osmose inversa

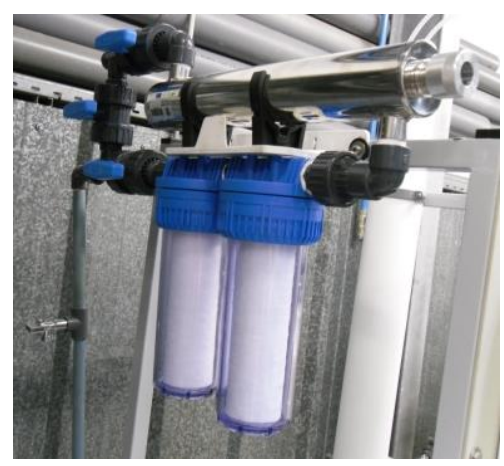

Figura 2 - Sistema de desinfeção por radiação ultravioleta

\section{RESULTADOS E DISCUSSÃO}

Os efluentes das indústrias de conservas de peixe são caracterizados por possuírem um elevado conteúdo de matéria orgânica, óleos e gorduras e sais (Garcia-Sanda et al., 2003). Os tratamentos convencionais permitem a remoção da matéria orgânica e dos óleos e gorduras; no entanto, são pouco eficazes na remoção de iões. Para obter água com a qualidade necessária para a sua reutilização e/ou reciclagem para a unidade industrial (Decreto-Lei No. 306/2007) é necessário um tratamento de 
afinação para remover a salinidade do efluente e os microrganismos nele ainda presentes. Os processos estudados para esse fim, foram filtração por membranas, osmose inversa e desinfeção por radiação ultravioleta. Para evitar a obstrução das membranas por partículas possivelmente presentes no efluente efetuou-se, em primeiro lugar, uma filtração através de um filtro rápido de areia, conseguindo uma remoção de SST apreciável (78\%). Em seguida estudou-se a remoção dos sais presentes no efluente por osmose inversa. Foram testadas 3 condições experimentais diferentes, como apresentado na Tabela 1. A pressão foi mantida entre 9,0 e 10,0 bar em todos os testes. Após a passagem do efluente pela membrana de osmose inversa efetuou-se uma análise completa do permeado. As remoções de COD, $\mathrm{N}_{\text {total solúvel }}$ e de condutividade atingidas em cada um dos testes são apresentadas também na Tabela 1.

Tabela 1 - Condições operacionais e resultados obtidos no tratamento por osmose inversa

\begin{tabular}{ccccccc}
\hline Testes & $\begin{array}{c}\text { Caudal de } \\
\text { permeado } \\
\text { (L/h) }\end{array}$ & $\begin{array}{c}\text { Caudal de } \\
\text { concentrado } \\
(\mathbf{L} / \mathbf{h})\end{array}$ & $\begin{array}{c}\text { Pressão } \\
\text { (bar) }\end{array}$ & COD & $\begin{array}{c}\text { Remoções (\%) } \\
\mathbf{N}_{\text {total }}\end{array}$ & Condúvel \\
\hline 1 & 192 & 204 & 9,0 & 89,6 & 95,0 & 98,4 \\
2 & 198 & 180 & 10,0 & 96,1 & 96,2 & 98,1 \\
3 & 216 & 60 & 9,0 & 97,3 & 99,8 & 99,1 \\
\hline
\end{tabular}

É possível verificar que, para pressões semelhantes, quanto maior o caudal de permeado e menor o caudal de concentrado, maior é a eficiência de remoção atingida para todos os parâmetros analisados. Assim, as máximas remoções de COD, $\mathrm{N}_{\text {total solúvel }}$ e de condutividade $(97,3 \%, 99,8 \%$ e $99,1 \%$, respetivamente) foram verificadas a um caudal de permeado de $216 \mathrm{~L} / \mathrm{h}$, a um caudal de concentrado de $60 \mathrm{~L} / \mathrm{h}$ e a uma pressão de 9,0 bar. Nestas condições, a remoção de catiões e aniões do permeado atingiu valores acima de 96\%. Na Tabela 2 apresentam-se as concentrações de COD, de

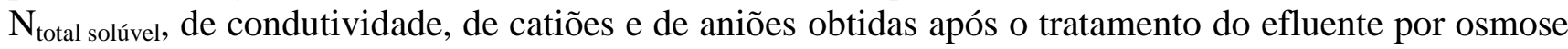
inversa, sendo possível verificar que todos os parâmetros se encontram abaixo dos valores ditados na legislação para águas de consumo humano (Decreto Lei No. 306/2007). 


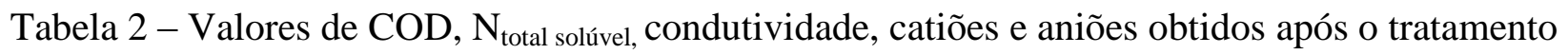
por osmose inversa.

\begin{tabular}{lc}
\hline \multicolumn{1}{c}{ Parâmetro } & Valor \\
\hline COD $(\mathrm{mg} / \mathrm{L})$ & 1,3 \\
$\mathrm{~N}_{\text {total solúvel }}(\mathrm{mg} / \mathrm{L})$ & 0,1 \\
Condutividade $(\mu \mathrm{S} / \mathrm{cm})$ & 50 \\
Lítio $(\mathrm{mg} / \mathrm{L})$ & $<\mathrm{LD}^{*}$ \\
Sódio $(\mathrm{mg} / \mathrm{L})$ & 8,0 \\
Amónio $(\mathrm{mg} / \mathrm{L})$ & 0,6 \\
Potássio $(\mathrm{mg} / \mathrm{L})$ & 0,6 \\
Magnésio $(\mathrm{mg} / \mathrm{L})$ & 0,2 \\
Cálcio $(\mathrm{mg} / \mathrm{L})$ & 1,5 \\
Cloreto $(\mathrm{mg} / \mathrm{L})$ & 6,1 \\
Nitrito $(\mathrm{mg} / \mathrm{L})$ & 0,3 \\
Sulfato $(\mathrm{mg} / \mathrm{L})$ & 0,1 \\
Brometo $(\mathrm{mg} / \mathrm{L})$ & 0,1 \\
Nitrato $(\mathrm{mg} / \mathrm{L})$ & $<\mathrm{LD}$ \\
Fosfato $(\mathrm{mg} / \mathrm{L})$ & 0,1 \\
\hline
\end{tabular}

*LD - Limite de deteção

Para assegurar a qualidade microbiana da água, de forma a poder ser reutilizada na unidade industrial, efetuou-se uma desinfeção por radiação ultravioleta do efluente proveniente do tratamento por osmose inversa nas melhores condições operatórias obtidas anteriormente. Por fim, recolheram-se algumas amostras do efluente antes e após a submissão à radiação UV e efetuou-se uma contagem de bactérias heterotróficas pelo método do espalhamento. Após o período de incubação, verificou-se que as amostras antes de serem submetidas ao tratamento de desinfeção ainda apresentam uma grande quantidade de microrganismos, como é possível ver pela Figura 3a. O tratamento com radiação UV é bastante eficiente, uma vez que as amostras não apresentaram quaisquer bactérias (Figura 3b). Após todos os tratamentos de afinação propostos, consegue-se obter um efluente final que cumpre os padrões de qualidade ditados para águas potáveis. 


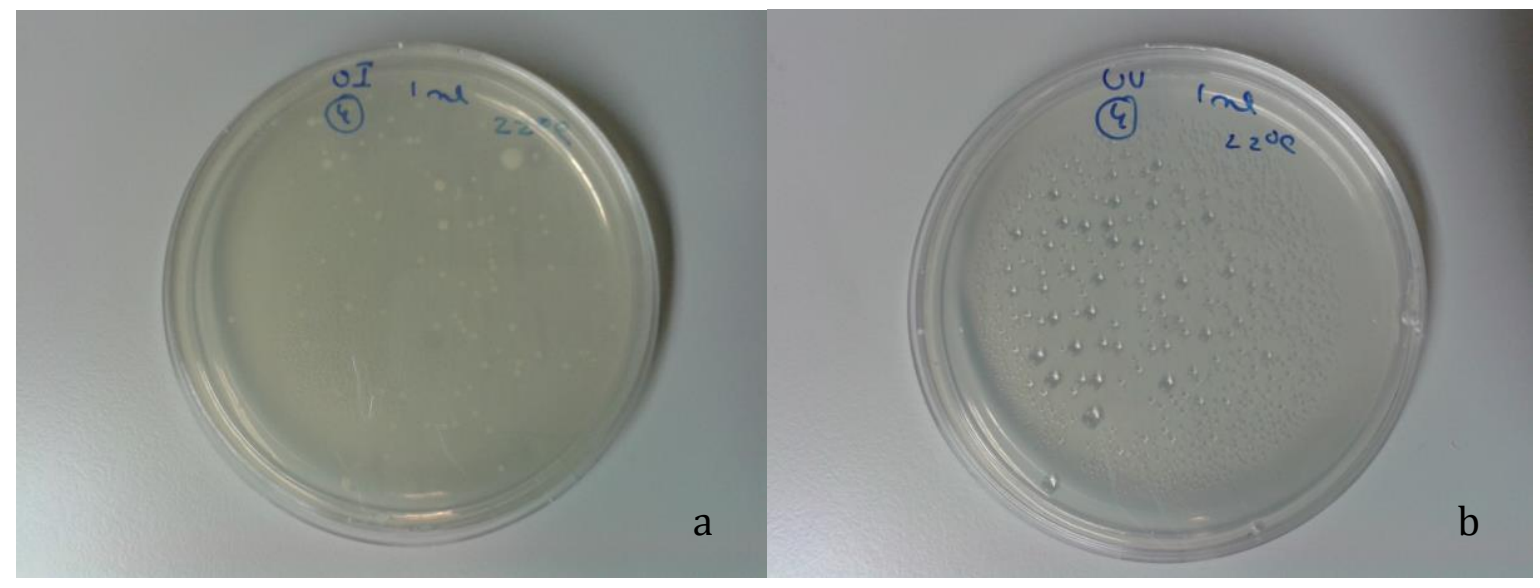

Figura 3 - Placas de Agar com amostras de efluente antes (a) e após (b) a desinfeção por radiação UV.

\section{CONCLUSÕES}

Neste trabalho estudou-se o tratamento de afinação de um efluente de uma indústria de conservas de peixe do norte de Portugal, de forma a ser possível a sua reutilização e/ou reciclagem para a unidade industrial. O sistema de tratamento proposto é composto por 3 etapas: uma etapa de filtração com um filtro rápido de areia, uma etapa de filtração com um processo de membranas por osmose inversa e, por fim, uma desinfeção por radiação UV. Após o estudo e otimização deste tratamento, foram obtidas remoções de $78 \%$ de SST com o filtro rápido de areia, 97,3\% de COD, $99,8 \%$ de $\mathrm{N}_{\text {total solúvel }}, 99,1 \%$ de condutividade e acima de $96 \%$ de aniões e catiões com o tratamento por osmose inversa e $100 \%$ de remoção de bactérias heterotróficas (UFC) com o tratamento de desinfeção por UV, levando a atingir o objetivo pretendido: uma água com a qualidade necessária para a reutilização e/ou reciclagem para a unidade industrial. Todos estes resultados mostraram a efetiva eficiência do sistema de clarificação proposto.

\section{AGRADECIMENTOS}

Este trabalho é parcialmente suportado pelo projeto PEst-C/EQB/LA0020/2013, financiado pela FEDER através do Programa Operacional Fatores de Competitividade - COMPETE e pela Fundação para a Ciência e a Tecnologia - FCT e pelo projeto em co-promoção I\&DT QREN $n^{\circ}$ 13634, ValorPeixe - Valorização de Subprodutos e Águas Residuais da Indústria de Conservas de Peixe, financiado pela FEDER através do Programa Operacional Fatores de Competitividade POFC aos quais os autores se encontram agradecidos. Os autores querem também agradecer à indústria de conservas em estudo pelas amostras de efluente. A autora Raquel O. Cristóvão agradece também à FCT pela bolsa de Pós-doutoramento (SFRH/BPD/81564/2011).

\section{REFERÊNCIAS}

AL-MUTAZ, I. S. A comparative study of RO and MSF desalination plants. Desalination, v. 106, p. 99-106, 1996. 
ALTAEE, A.; SHARIF, A. O. Alternative design to dual stage NF seawater desalination using high rejection brackish water membranes. Desalination, v. 273, p. 391-397, 2011.

APHA. Standard Methods for the Examination of Water and Wastewater. $21^{\text {st }}$ Ed. Washington, DC., United States of America, 2005

AWARENET. Handbook for the prevention and minimisation of waste and valorisation of byproducts in European agro-food industries, 2005.

CHOWDHURY, P.; VIRARAGHAVAN, T.; SRINIVASAN, A. Biological treatment processes for fish processing wastewater - A review. Biores. Technol., v. 101, p. 439-449, 2010.

COWI, Consulting Engineers and Planners AS. Cleaner Production Assessment in Fish Processing. UNEP, 2000

ELA, S. I. A.; NAWAR, S. S. Treatment of wastewater from an oil and soap factory via dissolved air flotation. Environ. Int., v. 4, p. 47-52, 1980.

GARCIA-SANDA, E.; OMIL, F.; LEMA, J. Clean production in fish canning industries: recovery and reuse of selected wastes. Clean Technol. Environ. Policy, v. 5, p. 289-294, 2003.

HIJNEN, W. A. M.; BEERENDONK, E. F.; MEDEMA, G. J. Inactivation credit of UV radiation for viruses, bacteria and protozoan (oo)cysts in water: A review. Water Res., v. 40, p. 3-22, 2006.

MISDAN, N.; LAU, W.J.; ISMAIL, A.F. Seawater Reverse Osmosis (SWRO) desalination by thin-film composite membrane - current development, challenges and future prospects. Desalination, v. 287, p. 228-237, 2012.

PELEKA, E. N.; MATIS, K. A. Application of flotation as a pretreatment process during desalination. Desalination, v. 222, p. 1-8, 2008

PEÑATE, B.; GARCÍA-RODRÍGUEZ, L. Current trends and future prospects in the design of seawater reverse osmosis desalination technology. Desalination, v. 284, p. 1-8, 2012.

RAUTENBACH, R.; MELLIS, R. Hybrid processes involving membranes for the treatment of highly organic/inorganic contaminated waste water. Desalination, v. 101, p. 105-113, 1995. 